\title{
VISÕES ANTAGÔNICAS NA REGULAMENTAÇÃO DA OUTORGA ONEROSA DO DIREITO DE CONSTRUIR NAS CIDADES DO RIO DE JANEIRO E SÃO PAULO
}

\author{
Eduardo Garcia Ribeiro Lopes Domingues* \\ Henrique Gaspar Barandier ${ }^{\dagger}$
}

\section{RESUMO}

Este artigo analisa a regulamentação da Outorga Onerosa do Direito de Construir nos planos diretores das duas maiores cidades do país, Rio de Janeiro e São Paulo, buscando compreender de que forma expressa uma visão política sobre a cidade. Através de metodologia exploratória e de revisão bibliográfica, apresenta breve estudo sobre o solo criado, a Outorga Onerosa, o Estatuto da Cidade e seus princípios para cotejar a Outorga nos Planos Diretores do Rio de Janeiro e de São Paulo e os princípios do Estatuto. Ao final, conclui que uma cidade incorpora os princípios do Estatuto da Cidade e outra não.

PALAVRAS-CHAVE: Política Urbana; Urbanismo; Direito Urbanístico; Estatuto da Cidade; Solo Criado.

\section{ANTAGONIC VIEWS IN THE REGULATION OF THE CHARGES FOR ADDITIONAL BUILDING RIGHTS IN THE CITIES OF RIO DE JANEIRO AND SÃO PAULO}

\begin{abstract}
This article analyzes the regulation of the Charges for Additional Building Rights in the master plans of the two brazilian largest cities, Rio de Janeiro and São Paulo, seeking to understand how this regulation expresses a political vision about the city. Through an exploratory methodology and bibliographic review, presents a brief study on the charges for additional building rights, the Statute of the City and its principles, in order to compare the regulation among the Master Plans of those two cities and the principles of the Statute. In the end, concludes that one city incorporates these principles and the other does not.
\end{abstract}

KEY-WORDS: Land Policy; Urbanism; Land Regulation; Statute of the City; Charges for Additional Building Rights.

\section{INTRODUÇÃO}

A Outorga Onerosa do Direito de Construir - OODC é um dos mais importantes instrumentos do Estatuto da Cidade - EC. Decorridos 17 anos da promulgação do Estatuto, cabe investigar como tem sido aplicada a OODC, que é fundamental para a gestão territorial

\footnotetext{
* Advogado. Doutor em Direito da Cidade - UERJ. Professor da Universidade Federal do Estado do Rio de Janeiro - UNIRIO, Graduação em Direito e Mestrado em Direito e Políticas Públicas. edomingues@unirio.br.

$\dagger$ Arquiteto e Urbanista, Doutor em Urbanismo - FAU/UFRJ. Coordenador Técnico e Professor do Instituto Brasileiro de Administração Municipal - IBAM. henrique.barandier@ibam.org.br.

Revista de Direito Urbanístico, Cidade e Alteridade | e-ISSN: 2525-989X | Salvador | v. 4 | n. 1 | p. 1 - 18 | 
urbana, com potencial de reduzir o valor da terra urbanizada. Outra vertente de utilização da OODC é o autofinanciamento de grandes empreendimentos, por meio do qual o Poder Público arrecada valores dos empreendedores para investir em obras no mesmo local onde se realiza o empreendimento.

O alcance desses objetivos depende da boa compreensão do instrumento e de sua correlação com os princípios constitucionais e legais de direito urbanístico. Ao mesmo tempo, observa-se que o emprego dos instrumentos urbanísticos encerra também uma visão política sobre a cidade e formas de regulação da produção urbana.

Neste artigo, parte-se da hipótese de que distintas visões políticas de cidade que moldaram os planos diretores das duas maiores cidades do país - São Paulo e Rio de Janeiro conduziram a formas divergentes de regulamentação da OODC. Essa questão é abordada aqui com a análise da disciplina da OODC nos Planos Diretores das duas cidades.

Para tanto, apresenta-se breve estudo sobre o solo criado; apontamentos sobre o surgimento do Estatuto da Cidade - EC e seus princípios e sobre a Outorga Onerosa do Direito de Construir; cotejamento entre os Planos Diretores dos Municípios do Rio de Janeiro e de São Paulo e os princípios do EC e considerações finais.

O estudo emprega metodologia exploratória, a partir de revisão bibliográfica, e análise comparativa dos Planos Diretores dos Municípios do Rio de Janeiro e de São Paulo por meio da fixação de parâmetros de análise, que serão explicitados no texto.

\section{SOLO CRIADO}

A ideia do solo criado surge na década de 70 (REZENDE, 2011) quando experiências de diversos países foram debatidas em três seminários realizados pelo Centro de Estudos e Pesquisas de Administração Municipal, da Fundação Prefeito Faria Lima, em 1976. O resultado desses seminários foi expresso na Carta de Embu. De acordo com Lira (1997), solo criado é:

[...] todo aproveitamento do terreno, no subsolo ou no espaço aéreo, envolvendo criação de solo, desde que consentido, implicará por parte do beneficiário na obrigação de dar à comunidade uma contraprestação por esse 
excesso de utilização, geralmente acompanhado de sobrecargas incidentes sobre os equipamentos urbanos (LIRA, 1997).

Essencialmente, o solo criado estabelece que a edificação acima de um determinado coeficiente de aproveitamento de terreno definido pela legislação municipal deva ser objeto de concessão onerosa e não gratuita, como era a prática corrente nas cidades brasileiras até a aprovação do Estatuto da Cidade e provavelmente ainda permanece sendo. A ideia central é que o direito de construir (ao menos em parte) pertence à coletividade e por isso deve ser adquirido pelos proprietários interessados em exercer o potencial construtivo admitido pela legislação urbanística que exceda o patamar básico. Essa abordagem seguia a interpretação europeia (francesa e italiana) do instrumento, tendo como perspectiva controlar os preços da terra e promover a redistribuição da valorização fundiária para combater a especulação imobiliária e a segregação urbana (RIBEIRO; CARDOSO, 1992).

No Brasil, o Estatuo da Cidade (2001) positivou a possiblidade de concessão onerosa do solo criado por meio da Outorga Onerosa do Direito de Construir (OODC). A OODC importa na concessão pública do direito de construir, que passa a ser gratuita apenas até um determinado limite - o coeficiente de aproveitamento básico - acima do qual incide a cobrança de contrapartida do interessado e daí o nome outorga onerosa. O coeficiente básico igual em toda a cidade tende a promover maior isonomia entre os terrenos de diferentes regiões. $\mathrm{E}$ a valorização diferenciada em razão de atribuição de potenciais construtivos máximos diferentes - o que pode se justificar por inúmeras razões - seria equalizada pela cobrança da outorga do direito de construir. Nessa linha de raciocínio, as áreas mais valorizadas, pagariam valores mais altos de outorga - exatamente por serem mais valorizadas -, confirmando o caráter potencialmente redistributivo do instrumento e contribuindo, se bem aplicados os recursos auferidos, para efetivação de uma das mais importantes diretrizes do Estatuto da Cidade: a "justa distribuição dos benefícios e ônus decorrentes do processo de urbanização", o que se verá a seguir.

De acordo com Rezende (2011), diversos argumentos jurídicos questionavam a constitucionalidade da cobrança sobre o solo criado, até que o Supremo Tribunal Federal STF decidiu pela sua constitucionalidade, explicitando o entendimento a respeito da natureza jurídica do instrumento: 
A OODC não é um imposto ou tributo, é um ônus vinculado à faculdade de exercer o direito de construir acima do coeficiente de aproveitamento básico, atribuível a proprietários de imóveis urbanos. (STF RE nº 387.047-5 - SC, Relator: Ministro Eros Grau)

Este ônus vinculado ao exercício da faculdade de construir acima do coeficiente básico é a recuperação da mais-valia fundiária, quer dizer, a recuperação de ganhos extraordinários que o particular aufere, para além do resultado do esforço empresarial, com a possiblidade de construir, que advém da legislação urbanística.

Em síntese, pode-se afirmar que os objetivos da cobrança pelo solo criado são impedir a total apropriação da mais-valia fundiária pelos proprietários de imóveis, bem como o de redistribuir os benefícios da urbanização para a coletividade.

\section{ESTATUTO DA CIDADE E OUTORGA ONEROSA DO DIREITO DE CONSTRUIR}

Até o advento do Estatuto da Cidade - EC, Lei n ${ }^{\circ}$ 10.257/2001, a aplicação do solo criado pelos Municípios era controvertida, sob argumento de que a Política Urbana deve seguir diretrizes gerais fixadas em lei nacional (CF, art. 182). Com sua promulgação, a regulamentação do solo criado através da OODC pelos Municípios passou a gozar de segurança jurídica, eis que disciplinada pela legislação nacional.

O Estatuto da Cidade - EC, Lei $n^{\circ} 10.257 / 2001$ constitui o marco legal e simbólico mais representativo de um processo de mobilização social e política em torno da luta pela reforma urbana. Esse movimento já tinha se destacado na Constituinte, por meio da proposição do capítulo sobre política urbana, que foi então acolhido na Constituição de 1988. Assim, juntamente com a redemocratização, vieram novas esperanças de atuação urbanística e de elaboração de um projeto nacional de desenvolvimento urbano (MOREIRA, 2002).

A grande preocupação da época era a construção de aparatos jurídicos que possibilitassem os Governos, em especial os municipais, implantarem políticas visando à justa distribuição dos benefícios da urbanização. O foco na legislação como forma de resolver os problemas urbanos partia da interpretação de que os problemas eram derivados da falta de 
planejamento e da falta de instrumentos legais para aplicação de políticas urbanas (ARANTES et. al., 2000).

O Estatuto da Cidade surge, portanto, com o propósito de suprir as falhas legislativas e de planejamento, munindo os Municípios de instrumentos jurídicos para atuar no ordenamento territorial e, por consequência, promoverem o acesso à cidade para todos.

A Constituição da República (1988) trouxe um arcabouço de princípios que resguardam os cidadãos e orientam a atuação do Poderes. Cabe destacar como de suma importância para a política urbana a dignidade da pessoa humana, insculpida na Constituição como fundamento da República (art. $1^{\circ}$, III), e também a construção de uma sociedade livre, justa e solidária $\left(\mathrm{CF}\right.$, art. $\left.3^{\circ}, \mathrm{I}\right)$ e a "erradicação da pobreza e da marginalização e a redução das desigualdades sociais e regionais" (CF, art. $3^{\circ}$, III), ambos positivados com objetivos fundamentais da República.

São esses fundamentos e objetivos que irão pautar a política de desenvolvimento urbano tratada na própria Constituição (art. 182), que deve ordenar o pleno desenvolvimento das funções sociais da cidade e garantir o bem-estar de seus habitantes. Desta forma, dignidade da pessoa humana, solidariedade, redução das desigualdades sociais são os mais relevantes princípios orientadores e motores da política urbana.

Observe-se que a Carta Constitucional tratou da Política Urbana no Capítulo II do Título VII (Da Ordem Econômica e Financeira), versando o Capítulo I sobre os Princípios Gerais da Atividade Econômica. Isto se dá porque a política urbana é política de atividade econômica, já que seu objeto (a segurança da habitação e os serviços públicos) são atividades econômicas.

Como bem analisou Grau (2010), o texto constitucional expressa uma ordem econômica, que contempla um sistema capitalista e um modelo econômico do bem-estar. A Constituição (art. 170) garante a propriedade privada, mas assegura o cumprimento da função social, garante livre iniciativa, a liberdade de constituição de empresa, o direito ao trabalho, mas o respeito às regras de mercado, ao direito do consumidor e a busca do pleno emprego.

Ora, de acordo com Domingues (2013), a atividade de urbanização é atividade econômica privada, sendo este o motivo da inclusão da política urbana no Título VII que trata da Ordem Econômica e Financeira. Por isso a política urbana se submete aos princípios do 
artigo 170 e à regra do artigo 174, que trata da fiscalização, incentivo e planejamento do Estado no que concerne às atividades econômicas. Para Grau (2010), a atividade econômica a que alude o artigo 174 é atividade econômica em sentido amplo, englobando a atividade econômica em sentido estrito e os serviços públicos. Segundo o autor, tal artigo se coaduna com os preceitos de uma Constituição programática sendo, portanto, papel do Estado normatizar e regular as atividades econômicas respeitando os ditames do sistema capitalista e propugnando a efetivação do modelo de bem-estar social.

Neste esteio, a União Federal, no exercício de sua competência concorrente (CF, art. 24 , I e $\S 1^{\circ}$ ), editou (e edita) normas gerais de direito urbanístico a que alude seu artigo 182 , incluindo-se, nesta seara, o Estatuto da Cidade. Logo no artigo $2^{\circ}$, o EC elenca como objetivos da política urbana a ordenação do "pleno desenvolvimento das funções sociais da cidade e da propriedade urbana".

Este artigo $2^{\circ}$ do Estatuto traça diretrizes gerais que devem estar em consonância com os mencionados princípios da dignidade da pessoa humana, solidariedade e redução das desigualdades sociais. Para fins deste estudo cabe destacar incisos do artigo $2^{\circ}$ que contém importantes diretrizes para aplicação da OODC, são eles: o inciso IV, que privilegia o "planejamento do desenvolvimento das cidades [...] de modo a evitar e corrigir as distorções do crescimento urbano e seus efeitos negativos sobre o meio ambiente; o inciso VI, alínea "c", que trata da ordenação e controle do uso do solo, de forma a "evitar o parcelamento do solo, a edificação ou o uso excessivos ou inadequados em relação à infra-estrutura urbana"; o inciso IX, que prevê a "justa distribuição dos benefícios e ônus decorrentes do processo de urbanização" e o inciso XI, que determina a "recuperação dos investimentos do Poder Público de que tenha resultado a valorização de imóveis urbanos”.

O EC trouxe os instrumentos legais a que Arantes et. al. (2000) faziam referência, possibilitando sua aplicação pelos Municípios. O artigo $4^{\circ}$ do EC elenca, dentre diversos instrumentos urbanísticos, a outorga onerosa do direito de construir e de alteração de uso (inciso V alínea "n"), cujo principal objetivo é a recuperação de mais-valias fundiárias decorrentes da criação de solo.

A outorga onerosa do direito de construir - OODC está disciplinada nos artigos 28 a 31 , onde se estabelece que sua previsão deve constar do plano diretor municipal, instrumento de planejamento que "poderá fixar áreas nas quais o direito de construir poderá ser exercido 
acima do coeficiente de aproveitamento básico adotado, mediante contrapartida a ser prestada pelo beneficiário" (art. 28). De acordo com o artigo 30 do EC, devem ser determinados por lei a fórmula de cálculo para a cobrança; os casos passíveis de isenção do pagamento da outorga e a contrapartida do beneficiário (EC, art. 30, I, II e III).

O EC disciplina nos artigos 32 a 34-A o instrumento das Operações Urbanas Consorciadas - OUC, que se vale do conceito de solo criado para obter recursos através da emissão de títulos pelo poder público municipal denominados certificados de potencial adicional de construção - CEPAC (art. 34), que serão negociados livremente e convertidos em direito de construir na área da OUC $\left(\operatorname{art.~} 34, \S 1^{\circ}\right)$. Os recursos auferidos com a CEPAC devem ser empregados pela Administração exclusivamente na própria área de abrangência da OUC (art. $33, \S 1^{\circ}$ ). Nesse caso, a cobrança da outorga do direito de construir se faz de modo antecipado, por meio dos CEPACs, e não no momento do licenciamento de cada projeto como ocorre com a OODC. Ao colocar à venda lotes de potencial construtivo na área da OUC, o poder público tem a capacidade de obter recursos para realização das intervenções planejadas.

Assim, esse dispositivo privilegiaria o mercado imobiliário já que a cobrança pela valorização do solo financiaria as intervenções e melhorias na sua própria área de atuação. Assim, o instrumento poderia contribuir para acirrar diferenças internas na cidade, viabilizando investimentos de grande porte concentrados em pequenas parcelas do território, que, consequentemente, seriam apropriados seletivamente pelas classes mais ricas. Esse efeito seria, portanto, contraditório a diretrizes do Estatuto da Cidade, em especial a da "justa distribuição dos benefícios e ônus decorrentes do processo de urbanização”.

Em outra perspectiva, se poderia argumentar que a tradição brasileira é de que o poder público sempre financiou diretamente, com recursos arrecadados de toda a sociedade, as grandes intervenções urbanas, sem cobrar nada dos beneficiários. Neste sentido, a delimitação de áreas em que os beneficiários da valorização futura antecipam recursos para o financiamento de obras tidas como importantes para a cidade poderia ser compreendida como uma novidade interessante. A questão de fundo seria, então, a de como caracterizar o interesse público com o projeto a ser implementado por meio de uma OUC e como efetivá-lo num quadro em que se mostra bastante difícil a conciliação entre interesses de mercado e a promoção de políticas inclusivas preconizadas pelo próprio Estatuto da Cidade. 
Tendo sido analisado o conceito de solo criado, estudados os princípios constitucionais da política urbana e a outorga onerosa do direito de construir no Estatuto da Cidade, passa-se à análise comparativa da disciplina da OODC nos Planos Diretores das cidades do Rio de Janeiro e de São Paulo.

\section{A OUTORGA ONEROSA DO DIREITO DE CONSTRUIR NOS PLANOS DIRETORES DO RIO DE JANEIRO E DE SÃO PAULO}

\subsection{PARÂMETROS DE ANÁLISE}

Tendo em vista os principais objetivos da OODC, de recuperar mais-valias fundiárias e de redistribuir os benefícios da urbanização, a presente análise comparativa busca verificar se os princípios e diretrizes expressos nos Planos Diretores - PDs do Rio de Janeiro e de São Paulo orientam o alcance de tais objetivos, bem como se a disciplina específica da OODC em cada um dos planos está em consonância com os objetivos da OODC e os princípios da política urbana do EC. Para tanto, a análise é feita em dois momentos distintos.

No primeiro momento, serão buscadas expressões nos PDs que indiquem correspondência com os objetivos de "recuperação de mais-valias fundiárias" e de "redistribuição dos benefícios da urbanização". No segundo momento, a análise da disciplina específica da OODC nos Planos Diretores não é feita por busca de expressões, mas sim por meio da interpretação sistemática da disciplina da OODC no próprio Plano Diretor em questão, buscando compreender a lógica de sua aplicação, o que inclui a verificação do(s) coeficiente(s) de aproveitamento básico(s) de terreno fixado(s).

O EC permite (art. $28, \S 2^{\circ}$ ) a adoção de coeficiente de aproveitamento básico único para a cidade ou de coeficientes diferenciados. De acordo com Rezende (2011) a doutrina não apresenta uniformidade de entendimento quanto à adoção de coeficiente único, embora toda a construção do solo criado se baseia na noção de coeficiente único (LIRA, 1997). Teoricamente, seria a solução mais lógica, pois cumpriria a função de equalizar diferenças resultantes da aplicação de índices urbanísticos diferenciados na cidade. No entanto, a concepção da legislação urbanística decorre de processo técnico-político que, via de regra, se refere a cidades existentes, práticas instituídas e um conjunto amplo de situações que podem conduzir a soluções próprias em cada contexto. Em todo caso, uma certa coerência entre os 
coeficientes básicos atribuídos numa mesma cidade deve existir. A análise dos PDs aqui desenvolvida, no seu segundo momento acima descrito, esta coerência entre os coeficientes básicos.

A escolha da comparação entre os Planos Diretores das Cidades do Rio de Janeiro e de São Paulo se deu em virtude de serem as duas maiores cidades do país e as duas com maior potencial de servirem de modelo para outras cidades. Igualmente, são Cidades de complexa dinâmica urbana, o que certamente influencia, cada qual com suas peculiaridades, o sistema de planejamento e a gestão do espaço urbano.

\subsection{ANÁliSE COMPRATIVA QUANTO À ADEQUAÇÃO DOS PDs ÀS} DIETRIZES DO ESTATUTO DA CIDADE

O Plano Diretor do Município do Rio de Janeiro foi aprovado pela Lei Complementar $n^{\circ}$ 111/2011, que dispôs sobre a Política Urbana e Ambiental do Município e instituiu o Plano Diretor de Desenvolvimento Urbano Sustentável. Também denominado de Plano Diretor da Cidade do Rio de Janeiro - PDCRJ (art. $1^{\circ}$, p. único), o documento está dividido em cinco títulos, a saber: I - Da Política Urbana; II - Da Ordenação do Território; III - Dos Instrumentos da Política Urbana; IV - Das Políticas Públicas Setoriais; e V Disposições Gerais, Transitórias e Finais.

Os artigos $2^{\circ}$ e $3^{\circ}$ do PDCRJ tratam, respectivamente, dos princípios e diretrizes da política urbana municipal. Nos princípios do artigo $2^{\circ}$ não foi localizada qualquer menção expressa à "recuperação de mais-valias" ou à "redistribuição dos benefícios da urbanização". O intérprete pode inferir que a "promoção da equidade social" (art. 2º I) e a "universalização do acesso à infraestrutura e os serviços urbanos" (art. $2^{\circ}$, IV) são implicitamente justificativas da utilização da OODC. Contudo, tal interpretação não há de ser tão elástica que permita afirmar serem essas expressões equiparáveis aos objetivos de recuperação de mais-valias e redistribuição dos benefícios da urbanização da OODC.

Igualmente, nas diretrizes do artigo $3^{\circ}$ do PDCRJ não se encontra expressa menção à "recuperação de mais-valias" ou à "redistribuição dos benefícios da urbanização". Os incisos V; XIII e XX podem ser considerados como fundamento indireto para aplicação da OODC, uma vez que tratam de questões envolvendo aplicação de recursos públicos em áreas 
desfavorecidas da Cidade. Esses incisos explicitam as diretrizes de urbanização das favelas (V); recuperação, reabilitação e conservação dos espaços livres públicos e do patrimônio construído em áreas degradadas ou subutilizadas (XIII) e ampliação da oferta habitacional de interesse social (XX).

A concretização dessas diretrizes estabelecidas no artigo $3^{\circ}$ é realizada através da aplicação dos instrumentos do Estatuto da Cidade, no qual se inclui a OODC. O artigo $7^{\circ}$ do PDCRJ, ao tratar da função social da propriedade urbana, determina a aplicação dos instrumentos do artigo $4^{\circ}$, incisos I a VI, do Estatuto da Cidade. Ainda o artigo $7^{\circ}$ do PDCRJ, sobre a função social da propriedade urbana, elenca em seu $\S 2^{\circ}$ as finalidades de aplicação dos instrumentos, confira-se:

$\S 2^{\circ}$ Os instrumentos referidos no $\S 1^{\circ}$ tem a finalidade de:

I - recuperar, em benefício coletivo, a valorização acrescentada pelos investimentos públicos à propriedade privada, através dos instrumentos legais pertinentes;

II - omitido;

III- promover a geração de recursos para a implantação de infraestrutura e de serviços públicos;

Neste parágrafo $2^{\circ}$ observa-se sintonia com um dos objetivos da OODC, a "recuperação de mais-valias". A determinação do inciso III, de geração de recursos para implantação de infraestrutura e serviços público não se assemelha perfeitamente à "redistribuição dos benefícios da urbanização", uma vez que não se direciona à áreas carentes, tampouco indica que os recursos serão advindos da OODC, embora essa possibilidade não fique também excluída. No segundo momento de análise será feita a aferição da congruência da fixação do(s) coeficiente(s) básico(s) com esta diretriz.

O Plano Diretor do Município de São Paulo foi aprovado pela Lei no 16.050/2014, que aprova a Política de Desenvolvimento Urbano e o Plano Diretor Estratégico do Município de São Paulo, designado neste estudo pela sigla PDESP. A Lei também dispõe sobre o Sistema de Planejamento Urbano (art. $1^{\circ}$ ), o documento, tal qual o do Rio de Janeiro, está dividido em cinco títulos, I - Da Abrangência, dos Conceitos, Princípios e Objetivos; II - Da Ordenação Territorial; III - Da Política e dos Sistemas Urbanos e Ambientais; IV - Da Gestão 
Democrática e do Sistema Municipal de Planejamento Urbano; e V - Das Disposições Finais e Transitórias.

Os artigos $5^{\circ}$ e $6^{\circ}$ tratam, respectivamente, dos princípios e das diretrizes da Política de Desenvolvimento Urbano e do Plano Diretor Estratégico, sendo elencados no artigo $7^{\circ}$ objetivos estratégicos. Nos princípios do artigo $5^{\circ}$ não foi localizada qualquer menção expressa à "recuperação de mais-valias" ou à "redistribuição dos benefícios da urbanização", no entanto, o inciso IV elenca a "Equidade e Inclusão Social e Territorial" e o inciso V o "Direito à Cidade", sendo ambos fundamentos da aplicação da OODC, na medida em que o $\S 4^{\circ}$ do mesmo artigo $5^{\circ}$ conceitua Equidade Social e Territorial como "redução das vulnerabilidades urbanas e das desigualdades sociais entre grupos populacionais e entre os distritos e bairros do Município" e o $\$ 5^{\circ}$ define o Direito à Cidade como "o processo de universalização do acesso aos benefícios e às comodidades da vida urbana". Desta forma, é clara a correlação entre este princípio e o objetivo de "redistribuição dos benefícios da urbanização", restando verificar se a positivação do princípio resultará numa regulação específica coerente.

O artigo $6^{\circ}$, que trata das diretrizes, elenca nos incisos I e II, respectivamente:

I - justa distribuição dos benefícios e ônus do processo de urbanização;

II - retorno para a coletividade da valorização de imóveis decorrente dos investimentos públicos e das alterações da legislação de uso e ocupação do solo;

Logo, fica patente a inclusão dos objetivos da OODC nas diretrizes do PDESP. A mesma análise realizada para o PDCRJ aponta dispositivos do artigo $6^{\circ}$ do PDESP que podem ser considerados como fundamento indireto para aplicação da OODC, uma vez que tratam de questões envolvendo aplicação de recursos públicos em áreas desfavorecidas da Cidade, como o inciso X, que indica o "incentivo à produção de Habitação de Interesse Social”.

No elenco dos objetivos estratégicos do artigo $7^{\circ}$, destaca-se o inciso XIII, que visa "reduzir as desigualdades socioterritoriais para garantir, em todos os distritos da cidade, o acesso a equipamentos sociais, a infraestrutura e serviços urbanos", correlacionando-se ao objetivo da OODC de "redistribuição dos benefícios da urbanização". 
Em relação ao coeficiente de aproveitamento básico do terreno, as diretrizes do artigo $6^{\circ}$ subsidiam sua fixação por meio dos incisos III, IV e XIII, que determinam a "distribuição de usos e intensidades de ocupação do solo de forma equilibrada" (III); a "compatibilização da intensificação da ocupação do solo com a ampliação da capacidade de infraestrutura" (IV) e a "ordenação e controle do uso do solo de forma a evitar" (XIII) "o parcelamento, a edificação ou o uso excessivos ou inadequados do solo em relação à infraestrutura urbana" (alínea b).

A função dos princípios e diretrizes do plano diretor é fundamentar e orientar a disciplina específica, a interpretação e aplicação da lei, cabendo aos objetivos a função de afunilar todo o escopo genérico e abstrato dos princípios e diretrizes de forma a delimitar sua incidência com um propósito específico incidente no território.

Assim, no que toca aos princípios e diretrizes do PDCRJ e do PDESP, é razoável não haver menção expressa à "recuperação de mais-valias" ou à "redistribuição dos benefícios da urbanização", eis que essas expressões são especificações de como se concretiza o pleno desenvolvimento das funções sociais da cidade e a garantia do bem-estar de seus habitantes inscritos no artigo 182 da Constituição. Por isso mesmo foram apenas identificadas expressões genéricas, tais como "promoção da equidade social e "universalização do acesso à infraestrutura e os serviços urbanos" (PDCRJ, art. $2^{\circ}$, I e IV) e "Equidade e Inclusão Social e Territorial" e "Direito à Cidade" (PDESP, art. $5^{\circ}$, IV e V e $\S \S 4^{\circ}$ e $5^{\circ}$ ) que vão fundamentar e orientar a disciplina, interpretação a aplicação da OODC, o que se coaduna com a função de princípios e diretrizes.

No caso do Município de São Paulo, além de a correlação dos princípios aos objetivos da OODC ter sido mais clara em razão da explicitação dos conceitos nos parágrafos do artigo $5^{\circ}$, o artigo $6^{\circ}$ explicitamente descreve como diretrizes a "justa distribuição dos benefícios e ônus do processo de urbanização" e o "retorno para a coletividade da valorização de imóveis decorrente dos investimentos públicos e das alterações da legislação de uso e ocupação do solo", assegurando tanto fundamentação quanto orientação para a OODC. No caso do Rio de Janeiro, princípios e diretrizes não explicitam fundamento ou orientação para a OODC, fazendo-o de forma implícita, se assim o quiser entender o intérprete. Em ambos os casos, é a análise da disciplina específica que mostrará a coerência interna dos PDs e a assimilação dos objetivos da OODC. 
Já quanto aos objetivos elencados em cada $\mathrm{PD}$, por se tratar da finalidade do planejamento, sua dicção comporta maior concretude, o que se verifica na indicação feita pelo PDCRJ das finalidades dos instrumentos do EC, dentre as quais "recuperar, em benefício coletivo, a valorização acrescentada pelos investimentos públicos à propriedade privada, através dos instrumentos legais pertinentes" (art. $\left.7^{\circ}, \S 2^{\circ}, \mathrm{I}\right)$, que traduz parte do conceito de "recuperação de mais-valias", que engloba a recuperação da valorização pelos investimentos públicos e também pela edição de legislação urbanística com indicação de índices construtivos. O PDCRJ apenas trata da mais-valia, nesta parte de objetivos, em relação aos investimentos públicos. No PDESP, um dos objetivos estratégicos é a redução das desigualdades socioterritoriais (art. $7^{\circ}, \mathrm{XIII}$ ), que, assim como no PDCRJ, expressa apenas uma das facetas da OODC, mas neste caso o objetivo de "redistribuição dos benefícios da urbanização".

Ambos os PDs têm indicativos que devem influenciar a fixação do(s) coeficiente(s) de aproveitamento básico(s), que, como dito, está relacionado com a sistemática da OODC. Mais uma vez, a análise da disciplina específica mostrará a coerência da legislação local.

\subsection{ANÁLISE COMPARATIVA DA DISCIPLINA ESPECÍFICA DA OODC NOS} PDs COM OS OBJETIVOS DA OODC

Antes de proceder à análise da disciplina específica da OODC nos PDs objeto deste estudo, cabe destacar que ambas as leis, em razão das diferenciadas dinâmicas urbanas presentes em cada cidade, estabelecem macrozonas que discriminam funções e usos para diferentes parcelas do território, bem como critérios para aplicação dos instrumentos do EC.

Como mencionado no item 4.1 deste estudo, a análise da disciplina específica da OODC é feita através da interpretação sistemática e da verificação dos coeficientes básicos de aproveitamento do terreno em cada PD.

No que diz respeito aos aspectos formais, ambos os PDs observam os requisitos do artigo 28 EC, indicando: as áreas passíveis de aplicação da OODC (PDCRJ art. 79, §2 Anexo IV e leis especiais; PDESP, art. 116 e Quadro 2A); o(s) coeficiente(s) de aproveitamento básico(s) (PDCRJ, art. 79 - Anexo VII; PDESP, art. 116, §2a , I) e os limites máximos (PDCRJ, art. 79 - Anexo VIII; PDESP, art. 116, §2ª). O EC determina em seu artigo 
30 que lei municipal específica irá estabelecer a fórmula de cálculo, eventuais isenções e a contrapartida. O PDCRJ indica (art. 81) que essas especificações serão previstas em lei posterior, enquanto o PDESP traz a fórmula de cálculo e a forma da contrapartida, não prevendo hipóteses de isenção. A disciplina no PDESP não afasta a necessidade de edição de lei municipal que torne efetiva a OODC, mas tem a vantagem de já consignar a complexa questão da fórmula de cálculo, evitando novas discussões a respeito que poderiam, no momento de edição da lei específica, inviabilizar a concretização da OODC.

Quanto aos aspectos materiais da OODC, a análise do conteúdo dos aspectos acima relatados (áreas de incidência, coeficientes de aproveitamento básico(s) e máximo(s)) evidencia o distanciamento de concepções das duas Cidades.

Em São Paulo, o plano diretor atual institui a OODC como instrumento geral, definindo o coeficiente de aproveitamento básico igual a 1,0 (um) para toda a cidade. Dessa forma o plano de 2014 concretiza significativo avanço em relação ao plano anterior, de 2002 (Lei 13.430/2002), que ainda previa coeficientes de aproveitamento básico diferenciados por zona. Naquele plano, aprovado apenas um ano após a entrada em vigor do Estatuto da Cidade, o coeficiente de aproveitamento básico podia ser 1,0 (um) ou 2,0 (dois), dependendo da zona, e em algumas zonas se podia chegar a dois na hipótese de determinados usos.

A cidade do Rio de Janeiro, curiosamente, trilhou o caminho inverso. Tinha um plano diretor de 1992 (Lei Complementar $\mathrm{n}^{\circ}$ 16/92), portanto anterior ao próprio Estatuto da Cidade, que definia o coeficiente de aproveitamento básico igual a um para cidade inteira, ainda que, na prática, tal coeficiente jamais tenha sido aplicado efetivamente. O plano diretor de 2011, revogando o anterior, instituiu, por sua vez, o coeficiente de aproveitamento básico diferenciado por zona, configurando grande retrocesso em relação à compreensão e ao alcance da OODC. Na verdade, o PDCRJ sequer utiliza a nomenclatura coeficiente de aproveitamento básico, o que contribui para dificultar o entendimento de como a OODC é disciplinada. O PDCRJ adota, como coeficiente de aproveitamento básico, o Índice de Aproveitamento de Terreno (IAT) que no plano de 1992 correspondia ao índice máximo de construção, mas que pelo plano vigente representa o básico. Assim, os IATs variam de 1,0 (um) a 15 (quinze), o que implica em grandes discrepâncias entre áreas da cidade, parecendo ser incoerente com princípios e diretrizes do Estatuto da Cidade, com o objetivo de recuperar mais-valias fundiárias e, consequentemente, com o objetivo de redistribuir os benefícios da urbanização. 
No caso de São Paulo, além do coeficiente de aproveitamento básico único, a concepção da OODC confirma seu caráter redistributivo ao atrelar os recursos auferidos com sua aplicação ao Fundo Municipal de Desenvolvimento Urbano (FUNDURB). De acordo com o PDESP, pelo menos 30\% dos recursos do FUNDURB serão aplicados na aquisição de terrenos destinados à produção de habitação de interesse social; e no mínimo 30\% "destinados à implantação dos sistemas de transporte público coletivo, cicloviário e de circulação de pedestre" (art. 340).

Já no Rio de Janeiro, o que se pode depreender é que, incidindo em áreas específicas da cidade - apenas aquelas demarcadas como "Áreas Sujeitas à Intervenção previstas no Anexo IV e definidas em Lei como Áreas de Especial Interesse Urbanístico ou de Operações Urbanas Consorciadas" (PDCRJ, art. 79, $\S 2^{\circ}$ ) - a OODC perde seu caráter geral para configurar-se prioritariamente como mecanismo para viabilização de determinados projetos. Apesar dos diferentes tipos de áreas nomeados, todas as situações conduzem à utilização da OODC apenas nos casos de OUCs. Dessa forma, como a OUC pressupõe que recursos da outorga onerosa sejam aplicados exclusivamente na área da operação para o financiamento das obras planejadas, o sentido redistributivo da OODC para a cidade é praticamente eliminado. Mais do que isso, tende a operar em sentido oposto, tornando-se mais um mecanismo concentrador de recursos em determinados espaços da cidade.

Na prática, quem quiser edificar na Cidade de São Paulo poderá fazê-lo utilizando o coeficiente de aproveitamento básico do terreno igual a 1,0 (um), sem necessidade de pagar qualquer contrapartida à municipalidade. Pagará contrapartida aquele que pretender edificar acima do coeficiente 1,0 (um), limitado ao coeficiente máximo de aproveitamento, que varia conforme a localidade da edificação.

Na Cidade do Rio de Janeiro, em regra, a edificação é livre de qualquer contrapartida, podendo o interessado se valer do IAT que varia conforme a localidade, entre 1,0 e 15, atribuindo-se, assim, diferentes valores aos imóveis sem concurso de ação dos proprietários. A cobrança de contrapartida pela edificação ocorrerá somente nas áreas sujeitas à OUC, sujeitas à voluntariedade da Administração. Entre fevereiro de 2004 e fevereiro de 2018, a soma dos valores disponibilizados pela Secretaria de Urbanismo do Município de São Paulo de arrecadação com a aplicação da outorga onerosa do direito de construir monta à quantia de $\mathrm{R} \$ 1.976 .105 .784,23$ (um bilhão, novecentos e setenta e seis milhões, cento e cinco mil, setecentos e oitenta e quatro reais e vinte e três centavos), sem contar nesse montante os 
valores arrecadados nas operações urbanas consorciadas por meio de Certificados de Potencial Adicional de Construção - CEPACs. Claramente, não são recursos desprezíveis, que se não fossem arrecadados pela municipalidade seriam apropriados pelos proprietários de terrenos e/ou incorporadores. Estes recursos servem para aplicação em todo o território da Cidade.

No Rio de Janeiro, de acordo com o site Porto Maravilha, a venda dos CEPACs foi realizada por leilão para viabilizar a OUC Porto Maravilha.

O vencedor do leilão foi o Fundo de Investimento Imobiliário Porto Maravilha (FIIPM), criado pelo Fundo de Garantia do Tempo de Serviço (FGTS) e administrado pela Caixa Econômica Federal, que arrematou o estoque de Cepacs do Porto Maravilha por R \$ 3,5 bilhões, ou $\mathrm{R} \$ 545$ cada título, além da preferência na compra de imóveis desapropriados pela prefeitura que consumam pelo menos $60 \%$ dos Cepacs. Ao comprar os títulos, o fundo assumiu o pagamento das despesas da operação urbana ao longo de 15 anos.

http://portomaravilha.com.br/artigosdetalhes/cod/10. Acessado em 27/03/2018.

Ressalte-se que este montante adveio de recursos dos Trabalhadores e não do setor imobiliário como ocorre no caso de São Paulo, e deve ser aplicado apenas na área do Porto, diferentemente de São Paulo em que a aplicação dos recursos pode vir a beneficiar toda a Cidade.

\section{CONSIDERAÇÕES FINAIS}

Pelo estudo empenhado, pode-se concluir que o Estatuto da Cidade trouxe um importante instrumento de gestão urbana, a OODC, que permite a recuperação pelo Poder Público de parte da mais-valia fundiária obtida pelo proprietário ao criar solo artificial, faculdade que lhe é assegurada pela legislação urbanística e, por isso mesmo, deve ser cobrada pelo Município como um ônus da atividade urbanística de edificação.

A OODC, se bem aplicada, garante ao Município recursos que podem ser redistribuídos para melhoras urbanísticas em áreas menos favorecidas da cidade. 
A análise comparativa dos Planos Diretores das duas maiores Cidades do País, por meio da busca de expressões e por análise de conteúdo específico almejava identificar a observância pelos PDs dos objetivos da OODC, "recuperação de mais-valias" e "redistribuição".

Na primeira parte, o PDESP mostrou grande correlação dos princípios elencados aos objetivos da OODC, enquanto que no PDCRJ princípios e diretrizes não explicitam fundamento ou orientação para a OODC. A análise da disciplina específica poderia mostrar coerência interna dos PDs e a assimilação dos objetivos da OODC, a despeito de, no caso do Rio de Janeiro, os princípios e diretrizes não apontarem expressamente este caminho.

Fato é que a análise da disciplina específica evidenciou uma discrepância entre os PDs das duas cidades. Enquanto em São Paulo a OODC é instrumento geral para toda a Cidade, definindo o coeficiente de aproveitamento básico igual a um, no Rio de Janeiro observa-se total descompasso da fixação dos coeficientes entre si e mesmo da relação entre eles e as diretrizes do próprio PDCRJ, na medida em que os coeficientes, IATs, são distribuídos em quantidades diferenciadas pela Cidade, com variações de um a quinze, afetando as possiblidades de edificação e de preço da terra, havendo como única possibilidade de OODC as intervenções públicas nas áreas de OUC.

A divergência aqui destacada é apenas uma, que mostra como a incorporação dos fundamentos do Estatuto da Cidade na gestão urbana no Brasil ainda dependerá de um longo percurso a ser percorrido. O entendimento sobre os instrumentos consagrados na lei federal permanecem em disputa e a utilização do potencial desses instrumentos, para incidir de forma consistente no mercado fundiário urbano, para contribuir para redução de desigualdades socioespaciais e para o financiamento do desenvolvimento urbano, permanece como grande desafio.

\section{REFERÊNCIAS}

ARANTES, Otília et al. A cidade do pensamento único. Desmanchando Consensos. $3^{\text {a }}$ ed. Petrópolis: Vozes, 2000.

DOMINGUES, Eduardo Garcia Ribeiro Lopes. Moradia não é Mercadoria. Revista de Direito da Cidade, [S.1.], v. 5, n. 1, p. 197-233, jun. 2013. Disponível em: <http://www.e- 
publicacoes.uerj.br/index.php/rdc/article/view/9729>. Acesso em: 21 mar. 2018. doi:https://doi.org/10.12957/rdc.2013.9729.

GRAU, Eros. Ordem Econômica na Constituição de 1988. São Paulo: Malheiros, 2010. LIRA, Ricardo Pereira. Elementos de Direito Urbanístico. Rio de Janeiro: Renovar, 1997. MOREIRA, Mariana. A História do Estatuto da Cidade. In: DALLARI, Adilson Abreu; FERRAZ, Sérgio (coord.). Estatuto da Cidade: comentários à Lei Federal 10.257/2001. São Paulo: Malheiros, 2002.

REZENDE, Vera F. et al. Revisão bibliográfica comentada dos fundamentos da Outorga Onerosa do Direito de Construir - OODC. Revista de Direito da Cidade, [S.1.], v. 3, n. 2, p. 156- 205, dez. 2011. Disponível em: <http://www.epublicacoes.uerj.br/index.php/rdc/article/view/9853>. Acesso em: 21 mar. 2018. doi:https://doi.org/10.12957/rdc.2011.9853.

RIBEIRO, Luiz César; CARDOSO, Adauto L. O solo criado como instrumento de reforma urbana: uma avaliação de seu impacto na dinâmica urbana. Ensaios FEE. Porto Alegre, 13, pp.370-381, 1992.

SANTOS JÚNIOR, Orlando Alves dos. et. al. O sistema nacional de desenvolvimento urbano: avanços e limites para a descentralização dos canais de participação. 2007.

Disponível em

<http://www.unmp.org.br/index.php?option=com_content\&view=article\&id=113:sistemanacional-de-desenvolvimento-urbano\&catid $=40$ :materiais-sobre-politica-dehabitacao\&Itemid=68>. Acessado em 20/03/2018.

SÃO PAULO. Secretaria de Urbanismo. Recursos do FUNDURB oriundos da arrecadação da Outorga Onerosa. Disponível em

http://www.prefeitura.sp.gov.br/cidade/secretarias/urbanismo/participacao_social/fundos/fund urb/index.php?p=202443. Acessado em 21 mar. 2018. 